\title{
SAÚDE MENTAL E PSICOLOGIA DO TRABALHO
}

\author{
José Roberto Heloani \\ Cláudio Garcia Capitão
}

Resumo: Este artigo objetiva, mediante algumas incursões teóricas e de uma análise sociopsicológica, discutir a forma como o trabalho está organizado em nossa sociedade, bem como as repercussões psíquicas provocadas pelo trabalho sem sentido. As condições e as exigências do mercado de trabalho na atualidade rotinizam e amortecem o sentido da vida, deixando no corpo as marcas do sofrimento, que se manifestam nas mais variadas doenças classificadas como ocupacionais, além de atentar contra a saúde mental.

Palavras-chave: psicodinâmica; trabalho; saúde mental.

Abstract: The objective of this paper is to discuss, trhough some theoretical incursions and a socio-psycological analysis, the way labor is organized in our society and the psychic repercussions criated by the non-sense labors. Conditions and requirements imposed by the current work market make life a matter of routine and deaden its sense, leaving scares of sufferings on bodies which are manifested by various diseases taken as occupational ones and constitute an attack to mental health.

Key words: psychodynamic; labor; mental health.

$\mathrm{U}$

m dos objetivos mais recentes da saúde mental não se restringe apenas à cura das doenças ou a sua prevenção, mas envidar esforços para a implementação de recursos que tenham como resultado melhores condições de saúde para a população.

$\mathrm{Na}$ visão de Bleger (1984), não interessa apenas a ausência de doenças, mas o desenvolvimento integral das pessoas e da comunidade. A ênfase, então, na saúde mental, desloca-se da doença à saúde e à observação de como os seres humanos vivem em seu cotidiano.

Para Dejours (1994), a psicopatologia tradicional está alicerçada no modelo clássico da fisiopatologia das doenças que afetam o corpo. Dedica-se, exclusivamente, ao diagnóstico das doenças mentais, dos transtornos mentais orgânicos, da esquizofrenia, dos transtornos do humor e dos inúmeros transtornos de personalidade. O debate, porém, que este artigo pretende explorar abrange as condições de milhares de pessoas sem imunidade que, embora suportem as pressões, conseguem, de alguma forma, escapar de um transtorno psicótico severo, mas que se mantêm, por assim dizer, no campo da normalidade.

Não é raro encontrar pessoas que, por uma condição de sua psicodinâmica interna, possuem a propensão a tra- balhar em excesso e a divertir-se muito pouco; outras, pelo contrário, passam os dias a divertirem-se; outras ainda não conseguem fazer nem uma coisa nem outra. Sabe-se hoje que tanto o trabalho, quanto a diversão em proporções satisfatórias são critérios para avaliar um funcionamento psíquico saudável.

Na realidade, ao contrário do que muitos possam supor, a organização do trabalho não cria doenças mentais específicas. Os surtos psicóticos e a formação das neuroses dependem da estrutura da personalidade que a pessoa desenvolve desde o início da sua vida, chegando a certa configuração relativamente estável, após o período de ebulição da adolescência - quando as condições sociais são relativamente favoráveis -, antes mesmo da pessoa entrar no processo produtivo. No entanto, "o defeito crônico de uma vida mental sem saída mantido pela organização do trabalho, tem provavelmente um efeito que favorece as descompensações psiconeuróticas" (Dejours, 1992:122).

Atualmente, observa-se uma pressão constante contra a grande massa de trabalhadores existente em quase todo o mundo. Uma ameaça com objetivo certeiro faz com que milhares de pessoas sintam-se sobressaltadas, pois a úni- 
ca ferramenta de que dispõem, sua força de trabalho, pode ser dispensada a qualquer momento.

O desprezo assola o universo do trabalho e traz consequiências drásticas para todos os que têm em seu trabalho sua única forma de sobrevivência.

Contudo, a força de trabalho exigida precisa de especial qualificação, mesmo que seja, como antigamente, para apertar um simples botão. Assim, para a maior parte das atividades, exige-se um trabalhador complexo, que saiba muito mais além do que seria preciso para a execução de determinada tarefa.

Acompanhando a tecnicidade do mundo, vai-se, paulatinamente, necessitando de um trabalhador com maiores habilidades, ágil, que saiba lidar com uma nova representação de mundo, mesmo que seja para ocupar um cargo simples como o de telefonista. Essa pessoa tem de dominar sua língua, em alguns casos outro idioma, tem de ter rapidez tanto manual, como na voz e na mente, além de uma bagagem de informação disponível enquanto recurso pessoal para, ante qualquer dificuldade, utilizá-la.

Assim, o mundo do trabalho torna-se, de forma rápida e surpreendente, um complexo monstruoso, que se por um lado poderia ajudar, auxiliar o homem em sua qualidade de vida, por outro lado - patrocinado pelos que mantêm o controle do capital, da ferramenta diária que movimenta a escolha de prioridades -, avassala o homem em todos os seus aspectos. Alguns são absorvidos, exigidos, sugados. Outros alçados a postos de poder e de liderança que reproduzem o capital virtual. Outros, por assim dizer, alguns milhões, são jogados como a escória cuja água benta do emprego, da possibilidade do trabalho, não veio a salvar.

Esse princípio de realidade adentra e fere o psiquismo humano, fazendo com que as pessoas sintam-se exigidas; o sentimento de impotência e de desvalorização, que leva as pessoas pouco resistentes a degenerar-se rapidamente, avilta de si qualquer potencial humano que pudesse se somar às conquistas da civilização.

\section{PARADOXOS DO TRABALHO}

A barbárie do capital instaura na contemporaneidade a desumanidade das relações humanas, que se desqualificam quase totalmente, surpreendendo com a forma e a fôrma na qual o homem atual vai colocando-se.

O capital, por meio do trabalho, organiza e estrutura o mundo. Só que hoje ele não tem mais nomes, expressa-se por Fundos. As empresas são gerenciadas por executivos, não mais por seus donos. Podem mudar de cidade, de nome, de país, de ramo de atividade, deixando seus trabalhadores em pleno mar de incertezas e retirando-lhes a identificação com sua prática diária e com a empresa para a qual trabalham.

No pensamento e análise precisos e pontuais de Ianni (2000), é principalmente no neoliberalismo que se dá a dissociação entre o Estado e a sociedade civil, adquirindo o primeiro características de um aparelho administrativo das classes e grupos que detêm o poder, configurando-se como blocos dominantes em escala mundial. O que se observa é um Estado comprometido com a possibilidade de facilitação da produção e dos mercados, tendo em seu bojo a fluidez do capital produtivo e especulativo, da alta tecnologia, da informática, etc. No entanto, sempre em sintonia com as políticas geradas pelo Fundo Monetário Internacional (FMI), Banco Mundial (Bird), Organização Mundial do Comércio (OMC), Grupo dos 7, Organização para a Cooperação e Desenvolvimento Econômico (OCDE) comprometidas em facilitar e incrementar a produção, com praticamente nenhum cuidado em relação aos resultados de suas políticas, sua repercussão social ou conseqüências diretas na vida de milhões de pessoas.

Se o homem passa a maior parte de seu tempo trabalhando, suas relações pessoais fora de casa deveriam ter um valor afetivo de extrema importância. No entanto, as relações de companheirismo e de amizade no trabalho não se concretizam, pois elas são passageiras, imediatas, competitivas e as ligações afetivas, os vínculos não podem estabelecer-se, já que com cada alteração rompem-se os laços, perdem-se as pessoas e daí, além do castigo do desemprego, há a solidão, a perda irreparável.

Fala-se em corrosão do caráter porque ninguém, nem os que teriam todas as razões para estarem satisfeitos com o sistema já que representam seu próprio ideal, encara seu emprego num horizonte a longo prazo. O comportamento de curto prazo, como Sennett (1998) observou, distorceu qualquer senso de realidade, confiança e comprometimento mútuo. As empresas descartam seus funcionários e os que podem fazem o mesmo. As pessoas parecem não mais estarem preocupadas com o significado do seu trabalho ou com a oportunidade de vivência e troca coletiva. A preocupação volta-se para a acumulação de um valor de troca, como se todos se convertessem em uma ação de mercado, cujo preço é julgado por outrem. A verdadeira identificação com o trabalho parece viver de um objetivo que não chega a concretizar-se: acumula-se aprendizado, dinheiro, experiência, aumentam-se as páginas do currícu- 
lo, tudo para o próximo processo seletivo já que o trabalho atual será apenas momentâneo.

No presente, ao contrário da classe de mineiros descrita em Germinal, por Zola, o que encontra-se são pessoas isoladas, esquizóides, que olham o colega como alguém não confiável, não só pelo fato do que o outro realmente é, mas, muito mais, pelo que representa: sofrimento e dor. No universo pós-moderno "são muitos os que colocam em plano muito secundário, ou simplesmente esquecem, o povo, as classes, os grupos e os movimentos sociais, assim como as correntes de opinião pública e os jogos das forças sociais [...] Em especial, esquecem as formas de organização social e técnica do trabalho, compreendendo as condições sob as quais se desenvolvem e realizam a produção, distribuição, troca e consumo, processos com os quais se funda uma parte fundamental da 'fábrica' da sociedade, em escala nacional e mundial” (Ianni, 2000).

Retrocedendo na História, assim como sugere Marx (1996), mais dependente aparece o indivíduo, e, conseqüentemente também o indivíduo produtor e o conjunto ao qual pertence. De início, esse aparece de um modo ainda bastante natural, no seio da família e da tribo, esta uma família ampliada. Mais tarde, surge nas inúmeras formas de comunidade resultantes do antagonismo e da fusão das tribos. Somente no século XVIII, na "sociedade burguesa", é que as diversas formas do conjunto social passaram a apresentar-se ao indivíduo como simples meio de realizar seus fins privados, como necessidade exterior. Todavia, a época que produz esse ponto de vista, o do indivíduo isolado, é precisamente aquela na qual as relações sociais (e, desse ponto de vista, gerais) alcançaram o mais alto grau de desenvolvimento.

Não pretende-se nesse breve artigo sobrepor o homem atual àquele encontrado no século XVIII, no que se refere, por exemplo, ao trabalho e à forma como ele se organiza. Mas, ao contrário, esclarecer algumas das determinações históricas que fizeram com que o trabalho fosse e tivesse a forma atual e porque a relação com o trabalho deve ser de sofrimento, de pena a ser cumprida, de trabalho forçado e não algo ego-sintônico, motivado e prazeroso. Seriam apenas as relações de propriedade e de exploração? Ou a própria produção cria aquele que consome, que, por sinal, cria a própria Produção.

Para Marx (1996:31), “a produção é também imediatamente consumo. Consumo duplo, subjetivo e objetivo. O indivíduo, que ao produzir desenvolve suas faculdades, também as gasta, as consome, no ato da produção, exatamente como a reprodução natural é um consumo de forças vitais".
Se a produção coincide com o consumo dos meios que obrigatoriamente foram utilizados e gastos para que ela ocorresse, o próprio ato de produção vai ser, como se verá, em todos os seus momentos, também ato de consumo. O resultado, em síntese, é que a produção é consumo, e que, imediatamente, é produção. "Cada qual é imediatamente seu contrário. Mas, ao mesmo tempo, opera-se um movimento mediador entre ambos. A produção é mediadora do consumo, cujos materiais cria e sem os quais não terá objeto. Mas o consumo é também mediador da produção ao criar para os produtos o sujeito, para o qual são os produtos" (Marx, 1996:32).

Para entender quais as determinações históricas da relação homem x trabalho na modernidade, tem-se de penetrar na "máquina" que tece sua trama nevrálgica, a produção que cria seu produtor e consumidor, com base no momento em que foi gerada.

Então, o trabalho configura-se como o representante da força dos impulsos que o homem emprega para executálo, para poder ou não consumir o que foi por ele produzido, abrindo possibilidades de constituição de subjetividades, correspondentes a cada época histórica, que tem, por domínio, uma forma de produção.

Sujeito, trabalho, produto, consumo, lucro. Elementos constitutivos de um intrigante eixo gravitacional, em que consumidor e produto mantêm uma relação eqüidistante. Para Adorno e Horkheimer (apud Rouanet, 1983:147) “a atrofia da imaginação e da espontaneidade do consumidor cultural moderno não precisa ser reconduzida a mecanismos psicológicos. Os produtos mesmos, a partir do mais típico, o filme falado, paralisam aquelas faculdades por sua própria constituição objetiva. São feitos de tal forma que sua compreensão adequada exige rapidez de reflexos, dotes de observação, competência específica, mas também a absoluta suspensão da atividade mental do espectador, se este não quer perder os fatos que se desenrolam diante de seus olhos... o espectador não deve trabalhar com a própria cabeça; o produto prescreve todas as reações: não por seu contexto objetivo - este se esvai no momento em que é submetido ao pensamento - mas através de sinais. Toda conexão lógica, que exija esforço intelectual, é escrupulosamente evitada”.

O produto posiciona o consumidor na mesma situação de uma linha de montagem e não se restringe apenas a filmes, mas a amplo universo de necessidades criadas, consumidas sem qualquer reflexão, como se os efeitos da paralisia mental sofrida na produção fosse transferida em gênero, número e grau, para aquele que o adquire. 
No que se refere à produção, e por que não dizer o mesmo para o consumo, a situação que se encontra na atualidade não surgiu por geração espontânea, mas ocorreram marcos no capitalismo, que, para melhor rendimento e maior produção, desenvolveu métodos, muitos dos quais, aperfeiçoados em diversas versões.

Taylor (apud Heloani, 1994) formulou uma forma de organização do trabalho caracterizada pelo amplo funcionamento das tarefas e concomitante o monitoramento dos movimentos dos trabalhadores. Tal forma rígida de controle objetivava a eficiência como meta e princípio. $\mathrm{O}$ modelo de Taylor, por seu lado, foi aperfeiçoado por Henry Ford, que desenvolveu a concepção de linha de montagem.

O trabalho, então, é dividido de tal forma que o trabalhador possa a ser abastecido de peças e componentes através de esteiras, sem precisar, desse modo, movimentar-se. A administração do tempo passa a se dar de forma coletiva, pela adaptação do conjunto dos trabalhadores ao ritmo imposto pela esteira. $\mathrm{O}$ fordismo não se limitará apenas à questão disciplinar no interior da fábrica. Ele incorporará, tal como o taylorismo, um projeto social de "melhoria das condições de vida do trabalhador". O projeto social fordista revela-se um projeto político que objetivava assimilar o saber e a percepção política do trabalhador para a organização.

Até a crise do paradigma taylorista-fordista de produção, o modelo de Recursos Humanos e a própria concepção de administração estiveram articulados com concepções oriundas da engenharia, especialmente com a de produção, como também, com a lógica militar, expressa tão bem pela utilização de vocábulos pertencentes à caserna, tais como: logística, tática, estratégia, etc.

Em consequiência das transformações sociais e das ocorridas no cerne do capitalismo, a abordagem da engenharia foi perdendo espaço e começou a ser questionada à medida que o modelo fordista de desenvolvimento entra em crise - perde sua eficácia - em fins dos anos 60 e começo dos 70. Tal mudança não foi produto simples e acabado de uma visão mais humanista ou de um longo e bem-cuidado processo de conscientização, mas consequiência de uma necessidade premente de responder a uma nova estrutura econômica e a um novo modo de regulamentação social; em suma, a uma nova realidade que se apresentava e que exigia respostas rápidas por parte do capital.

\section{QUALIDADE DE VIDA}

Hoje, o discurso manifesto encontrado nos folhetins que tratam das relações do trabalho parece demonstrar insis- tente preocupação com a melhoria da qualidade de vida dos que trabalham. Todavia, encontra-se uma política mundial de ajuste de custos que leva governos e empresas a minguarem as conquistas sociais alcançadas no último século pela classe trabalhadora.

Embora não exista uma definição consensual sobre a expressão "Qualidade de Vida no Trabalho (QVT)", o termo vem sendo utilizado com diferentes conteúdos e significados - sua origem, segundo Trist (1981), concerne a uma conferência internacional sediada em Arden House, em 1972, cujo tema principal versava sobre os "Sistemas Sociotécnicos". Não obstante, já no final da década de 50, quando o capital americano promove uma recessão para organizar o seu parque industrial, observa-se certa preocupação com esse assunto nos países que ditavam a política do capitalismo. Não teria portanto o "movimento" de QVT sua verdadeira origem nas conseqüências sociais da primeira retração econômica significativa após a Segunda Guerra Mundial nos EUA? É o que parece, ainda que tais mazelas só possam ser conhecidas e sentidas em sua real magnitude na crise do modelo de desenvolvimento fordista dos anos 60 e 70 .

O que se constata é que a qualidade de vida do trabalhador, especialmente dos que vivem no terceiro mundo, vem-se degradando dia após dia. Doenças até então inexistentes ou restritas a certos nichos empresariais, como a LER/Dort tornaram-se comuns a todos, e espalharam-se como doenças infecto-contagiosas, tornando impossibilitados, para o trabalho, milhares de trabalhadores. As Lesões por Esforços Repetitivos (LER) ou Distúrbios Osteomusculares (Dort) relacionados ao trabalho são nomenclaturas utilizadas para designar inúmeras doenças, entre as quais tenossinovites e tendinites, ou seja, inflamações que se manifestam nos tendões e nas bainhas nervosas que os recobrem; são afecções que podem acometer músculos, tendões, nervos e ligamentos de forma isolada ou associada, com ou sem a degeneração de tecidos, e que pode ocasionar a invalidez permanente. Em geral, não são facilmente diagnosticadas - o que prejudica o processo de tratamento - e afetam sobretudo trabalhadores do sexo feminino, das mais variadas atividades, com maior incidência entre os dezoito e trinta e cinco anos. Parece até que, pelo encolhimento do mercado de trabalho, as lutas dos trabalhadores restringem-se apenas à sobrevivência, assim como o quadro histórico encontrado no início do século passado, em que a luta era para não morrer, não importando o preço que teria de ser pago... viver como um estado apenas emergencial. 
No entanto, se a qualidade de vida do trabalhador é vista, pelo menos como uma política de relações públicas, ou como uma meta quase recorrente, deve-se perguntar o que no trabalho pode ser apontado como fonte específica de nocividade para a vida mental. A trama em que essa questão está envolta é quase evidente: a luta pela sobrevivência leva a uma jornada excessiva de trabalho, e as condições em que o trabalho se realiza repercutem diretamente na fisiologia do corpo.

O rompimento de vínculos de relações fundamentais para manutenção e fortalecimento da subjetividade humana atua de certa forma que pode desencadear o assédio moral, o qual tem sido compreendido, atualmente, como a exposição dos trabalhadores a situações humilhantes e constrangedoras, repetitivas e prolongadas durante a jornada de trabalho; e passam a ser mais desestabilizadoras. Mesmo assim, logo as relações ficam mais desumanas e aéticas, nas quais predominam os desmandos, a manipulação do medo, a competitividade desenfreada e os programas de qualidade total associados à produtividade $\mathrm{e}$ dissociados da QVT. A qualidade total sem qualidade de vida não é integral, mas parcial.

O trabalho como regulador social é fundamental para a subjetividade humana, e essa condição mantém a vida do sujeito; quando a produtividade exclui o sujeito podem ocorrer as seguintes situações: reatualização e disseminação das práticas agressivas nas relações entre os pares, gerando indiferença ao sofrimento do outro e naturalização dos desmandos administrativos; pouca disposição psíquica para enfrentar as humilhações; fragmentação dos laços afetivos; aumento do individualismo e instauração do pacto do silêncio coletivo; sensação de inutilidade, acompanhada de progressiva deterioração identitária; falta de prazer; demissão forçada; e sensação de esvaziamento.

As condições laborais, bem como as relações diretas entre os trabalhadores, influenciam diretamente a qualidade de vida. Essa, portanto, torna-se, nessa perspectiva, estratégica para a sobrevivência e desenvolvimento futuros das organizações.

Como a produção estimula o consumo e ao mesmo tempo inventa o sujeito para o qual ela se destina, deve, então, esse sujeito, receber os impactos diretos da organização do trabalho. Resta, então, deduzir que, em grande parte, o sofrimento mental do trabalhador é consequiência direta dessa organização, isto é, da divisão do trabalho, do conteúdo da tarefa, do sistema hierárquico, das modalidades de comando, das relações de poder, etc.; de todo um apa- rato que modula a percepção, o controle dos impulsos, as possibilidades de apreensão e a reflexão do que produz e que também se consome nas tarefas que executa.

\section{O SOFRIMENTO DO TRABALHO}

Dejours (1992) afirma que executar uma tarefa sem envolvimento material ou afetivo exige esforço de vontade que em outras circunstâncias é suportado pelo jogo da motivação e do desejo. A vivência depressiva em relação ao trabalho e a si mesmo alimenta-se da sensação de adormecimento intelectual, de esclerose mental, de paralisia da fantasia e da imaginação; na verdade, marca de alguma forma o triunfo do condicionamento em relação ao comportamento produtivo e criativo. Para esse pensador, no que diz respeito à relação do homem com o conteúdo significativo do trabalho, é possível considerar, esquematicamente, dois componentes: o conteúdo significativo em relação ao sujeito e o conteúdo significativo, pode-se assim dizer, em relação ao objeto. Quando o progresso e o avanço dessa relação são bloqueados por algum motivo ou circunstância, observa-se a incidência do sofrimento.

O sofrimento, por seu turno, é desdobrado: o ponto de incidência proveniente das ações mecânicas, conteúdo ergonômico da tarefa, é o corpo e não o aparelho mental; esse último será afetado pela insatisfação propiciada pelo conteúdo significativo da tarefa a ser executada, transformando em sofrimento bem particular, cujo alvo, antes de tudo, é a subjetividade, ou seja, a mente.

Freud (1987a), ao descrever o desenvolvimento psíquico, relata que uma criança recém-nascida ainda não diferencia seu ego do mundo externo como origem das inúmeras sensações que são vivenciadas por ela; apenas, com o passar do tempo, e progressivamente, vai aprendendo a fazer tal diferenciação, reagindo de modo adequado aos estímulos correspondentes. Por seu lado, o ego, movido pelo princípio do prazer, tenta afastar as sensações desprazerosas, denotanto uma tendência a isolar e a projetar para fora de si tudo o que pode ser fonte de desprazer. Num estágio de maior integração, o ego, com a ação deliberada das atividades sensórias e da ação muscular correspondente, consegue diferenciar entre o que é interno e o que origina-se do mundo externo, estabelecendo dessa forma as condições para a introdução do princípio de realidade. Por meio desse último, o ego pode localizar o sofrimento surgindo de três direções: de nosso próprio corpo, do mundo externo e da nossa relação com as outras pessoas. 
Esses desdobramentos na evitação do sofrimento por parte do ego podem também ocorrer em relação ao trabalho, tanto do ponto de vista físico quanto mental. O trabalho, não só como uma condição externa, pode propiciar sofrimento insuperável para o ego, empobrecendo-o e restringindo sua ação a mecanismos defensivos repetitivos e ineficazes, não lhe possibilitando aferir, de acordo com suas atividades, a satisfação de determinadas pulsões, que, não satisfeitas, tensionariam o aparelho psíquico, gerando angústia, estados depressivos, ansiedade, medos inespecíficos, sintomas somáticos, como sinais marcantes de sofrimento mental, com o agravante de que um ego debilitado e frágil não consegue diferenciar, pela sua condição, a origem de seu sofrimento.

Dejours (1994) distingue dois tipos de sofrimento: o sofrimento criador e o sofrimento patogênico. Este último surge quando todas as possibilidades de transformação, aperfeiçoamento e gestão da forma de organizar o trabalho já foram tentadas, ou melhor, quando somente pressões fixas, rígidas, repetitivas e frustrantes, configuram uma sensação generalizada de incapacidade.

Todavia, quando as ações no trabalho são criativas, possibilitam a modificação do sofrimento, contribuindo para uma estruturação positiva da identidade, aumentando a resistência da pessoa às várias formas de desequilíbrios psíquicos e corporais. Dessa forma, o trabalho pode ser o mediador entre a saúde e a doença e o sofrimento, criador ou patogênico.

Assim, prazer e sofrimento originam-se de uma dinâmica interna das situações e da organização do trabalho. São decorrências das atitudes e dos comportamentos franqueados pelo desenho organizacional, cuja tela de fundo constitui-se de relações subjetivas e de poder.

Pela condição de funcionamento mental estabelecida, o sujeito perde sua autonomia e, por conseqüência de um ego debilitado, não tem forças para realizar o trabalho de reflexão em que está envolvida toda sua existência, pois "as variáveis de personalidade mais relevantes na determinação da objetividade e racionalidade da ideologia são as pertencentes ao Ego, a parte da personalidade que avalia a realidade, integra as demais instâncias, e opera da forma mais consciente. É o ego que percebe as forças nãoracionais que atuam na personalidade, e se responsabiliza por elas" (Adorno; Horkheimer, apud Rouanet, 1983:170).

Nesse sentido, abre-se ao psicólogo, e aos demais profissionais de saúde mental, um campo enorme de estudo, não apenas de denúncia. As condições e as exigências do mercado de trabalho na atualidade rotinizam e amortecem o sentido da vida, deixando no corpo as marcas do sofrimento, que se manifestam nas mais variadas doenças ditas ocupacionais, além de atentar contra a saúde mental, em especial quando o psiquismo anquilosado em sua mobilidade faz com que a mente seja absorvida em formas de evitação do sofrimento.

No entanto, as organizações cobram de seus psicólogos e das escolas que os formam um rápido ajustamento de suas metodologias e de suas estratégias de ação. Isso tem feito com que grande parte dos psicólogos organizacionais abracem novamente (sem nenhuma crítica, com pouquíssima reflexão) idéias, princípios e pressupostos vindos das teorias administrativas, tais como as chamadas "Teorias da Qualidade", verdadeiro fetiche pós-moderno, pois nada mais são do que a reatualização de alguns princípios da década de 30 , bem untados com uma eficiente metodologia quantitativa desenvolvida na década de 50, aproveitada nos anos 70 e aperfeiçoada na década de 80 .

Na realidade, com o esvaziamento da área de Recursos Humanos, em razão das reengenharias, processos de downsizing e congêneres, alguns psicólogos estão-se transformando em consultores internos, assessorando treinamento e seleção e passando da posição de linha para a de staff, que além de ser, no cômputo geral, menos custosa, possui a vantagem do não envolvimento direto com os trabalhadores.

Como nas organizações pós-fordistas houve uma maquiagem no que concerne ao controle. Agora o psicólogo não regula o processo, o controle é por resultados, o compromisso é com a qualidade e esse profissional deve voltar sua atenção para a auto-regulação do trabalhador. Essa sim é sua função! Não há nada de mais democrático ou participativo nisso em relação à concepção taylorista/fordista. O que existe é a substituição do controle externo do desempenho pelo controle interno dos próprios funcionários mediante eficiente trabalho de comunicação no qual o psicólogo, sem dúvida, poderá vir a ser protagonista, pois compete a ele, agora, instruir as equipes nesse sentido.

Nas empresas pós-fordistas, signatárias do neoliberalismo, a matéria-prima principal são as pessoas; a moeda mais importante é o signo e o símbolo, e a manipulação dos processos psicodinâmicos constitue a principal tecnologia. Essas são algumas das ferramentas da empresa pós-moderna (se é permitido o neologismo). Substituíram o chicote, o supervisor e os testes psicológicos pela ilusão da integração e da participação. É a tentativa da construção de uma nova subjetividade que encontra no 
projeto neoliberal a sementeira do individualismo e da barbárie.

\section{CONCLUSÃo}

Pelos problemas aqui abordados, as questões que envolvem a psicodinâmica do trabalho tornam-se pontos fundamentais de preocupação para os que lidam com Saúde Pública, sobretudo quando se sabe que a separação entre mente e corpo é apenas uma questão semântica, didática, e que o conceito de saúde vai muito além do que a mera ausência sintomática de doenças.

Quanto à psicologia, concorda-se com Freud (1987b:61) quando assinala que "um psicólogo que não se ilude sobre a dificuldade de descobrir a própria orientação neste mundo, efetua um esforço para avaliar o desenvolvimento do homem, à luz da pequena porção de conhecimentos que obteve através de um estudo dos processos mentais de indivíduos durante seu desenvolvimento de criança a adulto". Não se pode ser fiador de futuras ilusões para a grande massa de trabalhadores, que sofre com o trabalho ou com a sua falta.

O trabalho não pode ser uma negatividade da vida, mas, muito pelo contrário, sua expressão, coisa que o capitalismo, em suas mais variadas versões apresentadas no decorrer da história, não permitiu que ocorresse. Eis a Esfinge que cabe ao homem contemporâneo decifrar, para não ser definitivamente devorado por ela.

\section{REFERÊNCIAS BIBLIOGRÁFICAS}

BLEGER, J. Temas de psicologia: entrevista e grupos. São Paulo: Martins Fontes, 1989.

DEJOURS, C. Psicodinâmica do trabalho. São Paulo: Atlas, 1994. . A loucura do trabalho. São Paulo: Cortez, 1992.
Repressão e subversão em psicossomática: pesquisa psicanalítica sobre o corpo. Rio de Janeiro: Zahar, 1989. . O corpo entre a biologia e a psicanálise. Porto Alegre: Artes Médicas, 1988.

FREUD, S. O mal-estar na civilização. Rio de Janeiro: Imago, 1987a (Obras Completas, v.21).

. O futuro de uma ilusão. Rio de Janeiro: Imago, 1987b (Obras Completas, v.21).

HELOANI, J.R. Organização do trabalho e administração: uma visão multidisciplinar. São Paulo: Cortez, 1994.

IANNI, O. Enigmas da modernidade-mundo. Rio de Janeiro: Civilização Brasileira, 2000.

LARANJEIRA, S.M.G. A realidade do trabalho em tempo de globalização. Precarização, exclusão e desagregação social. In: SANTOS, J.V.T. (Org.).Violência em tempo de globalização. São Paulo: Hucitec, 1999.

MARX, K. Para a crítica da economia política do capital. São Paulo: Nova Cultural, 1996.

MATTAR Jr. R.; AZZE, R.J. Moléstias ocupacionais, lesões por esforços repetitivos: um desafio para a cirurgia de mão. In: CODO, W.; ALMEIDA, M.C.C.G. (Orgs.). LER: diagnóstico, tratamento e prevenção. Petrópolis: Vozes, 1997.

PAGÈS, M. et al. O poder das organizações: a dominação das multinacionais sobre os indivíduos. São Paulo: Atlas, 1993.

RIFKIN, J. O fim dos empregos. São Paulo: Makron Books, 1995.

ROUANET, P.S. Teoria crítica e psicanálise. Rio de Janeiro: Tempo Brasileiro; Fortaleza: Edições Universidade Federal do Ceará, 1983.

SENNETT, R. The corrosion of character. New York: W.W. Norton, 1998.

TRIST, E. The evolution of socio-technical systems. Ontario-Toronto: Quality of Working Life Centre, 1981.

WALTON, R.E. Improving the quality of working life. Harvard Business Review, USA, May-Jun. 1974.

Quality of working life: what is it? Sloan Management Review, Cambridge, v.15, n.1, 1973.

José Roberto Heloani: Professor e Pesquisador da Universidade Estadual de Campinas ena FGV-SP(jheloani@ fgvsp.br).

Cláudio Garcia Capitão: Psicólogo Clínico, Professor e Pesquisador em Psicologia na Universidade São Francisco (cgcapitao@uol.com.br). 